\title{
长链非编码RNA调控流感病毒感染致病的作用
}

\author{
闵洁 ${ }^{1,2}$, 曹影 ${ }^{1,3}$, 李晶 ${ }^{1,2 *}$, 刘文军 ${ }^{1,2 *}$
}

1. 中国科学院微生物研究所病原微生物与免疫学重点实验室, 北京 100101 ;

2. 中国科学院大学, 北京 100049 ;

3. 中国科学技术大学生命科学学院, 合肥 230000

*联系人, E-mail: 1j418@163.com; liuwj@im.ac.cn

收稿日期：2018-09-25; 接受日期：2018-10-11; 网络版发表日期：2018-12-11

国家重点研发计划(批准号: 2016YFD0500206)和国家自然科学基金(批准号: 31630079)资助

摘要 长链非编码RNA(long non-coding RNAs, lncRNAs) 是一类转录本长度超过 $200 \mathrm{nt}$ 的RNA分子, 参与转录前 调控、转录调控及转录后调控等生命活动. 流感病毒的宿主谱较为广泛, 能感染人、禽类、马(Equus caballus) 和 猪(Sus) 等动物, 曾引起多次世界性大流行, 持续给人类健康、畜禽养殖造成重大威胁, 且与宿主互作机制十分复 杂。近年来研究表明, 流感病毒感染宿主过程中能诱导机体产生大量IncRNAs, 这些IncRNAs能与多种生物大分子 互作, 直接或间接在宿主的抗病毒途径或流感病毒的复制中发挥着重要调控作用. 揭示这些IncRNAs在流感病毒 感染、复制等过程中的功能, 对于阐明流感病毒的致病机制具有重要意义. 鉴于此, 本文对在流感病毒感染中发 挥重要调控作用的IncRNAs进行综述, 旨在增强我们对lncRNAs的认识, 为流感的防控提供借鉴和参考.

关键词 流感病毒, 长链非编码RNA, 感染致病, 天然免疫

A型流感病毒(influenza A virus, IAV)是引起流感 爆发的主要病原, 曾引起4次世界性大流行并导致每年 爆发季节性流行病，从1918年的西班牙流感到2009年 的猪流感，再到2018年季节性流感，上千万人死于流 感爆发, 畜禽捕杀不计其数, 给人类健康和畜禽养殖 造成重大威胁并产生经济损失 ${ }^{[1 \sim 3]}$. 随着高通量测序等 现代生物技术的高速发展，长链非编码RNAs(long non-coding RNAs, lncRNAs)的重要生物学功能逐渐被 研究人员认识. 长链非编码RNAs是一类转录本长度超 过 $200 \mathrm{nt}$ 的RNA分子 ${ }^{[4]}$, 它们大多数被认为缺乏编码蛋 白质的能力, 以RNA的形式在多种层面上如表观遗传
调控、转录调控以及转录后调控等调控基因的表达水 平. 目前, 超过 $98 \%$ 的人类基因组被转录成非编码RNA (ncRNAs), 而大部分的转录本归为长链非编码RNAs $(\operatorname{lncRNAs})^{[5]}$. 在过去几年间, 在SARS冠状病毒(SARS$\mathrm{CoV}$ )感染的小鼠(Mus musculus)体内和IAV感染的人 类肺脏细胞内发现了数以千计的 $\operatorname{lncRNAs}{ }^{[6-8]}$. 如此数 量庞大的IncRNAs在常见病毒感染的细胞或宿主体内 差异性的表达, 提示lncRNAs在宿主细胞内所发挥的 重要作用.

随着对lncRNAs研究的深入, lncRNAs可参与 DNA, RNA或蛋白结合, 调控转录、mRNA稳定和蛋

引用格式: 闵洁, 曹影, 李晶, 等. 长链非编码RNA调控流感病毒感染致病的作用. 中国科学: 生命科学, 2018, 48: 1263-1272

Min J, Cao Y, Li J, et al. Regulation of influenza virus infection by long non-coding RNAs (in Chinese). Sci Sin Vitae, 2018, 48: 1263-1272, doi: 10.1360/N052018-00190 
白质翻译等生物学过程 ${ }^{[9]}$. 值得关注的是, 近年来 lncRNAs调控流感病毒与宿主相互作用的报道越来越 多, 研究lncRNAs的功能及其与病毒致病性之间的关联 显得尤为重要. 因此, 本文对流感病毒感染中发挥重要 调控作用的lncRNAs加以综述, 旨在加强对lncRNAs的 认识, 为流感病毒的基础研究提供借鉴和参考.

\section{1 长链非编码RNA的基本特性}

\subsection{IncRNAs的基本概念和特性}

IncRNAs 是RNA聚合酶 II 或III作用下的转录产 物, 具有 $5^{\prime}$ 端帽子且有或无 $3^{\prime}$ 端聚腺苷酸化尾部 ${ }^{[10]}$. 基 于基因组位置的差异及其与邻近蛋白质编码基因的关 系, $\operatorname{lncRNAs}$ 分为正义、反义、双向、内含、基因 间、转录的伪基因 $1 \mathrm{ncRNAs}$ 以及增强子 $\mathrm{RNA}$ $(\mathrm{eRNA})^{[11,12]}$. IncRNAs主要分布在细胞核、细胞质及 外泌体中, 与mRNA相比, IncRNAs序列保守性较差, 表达具有细胞特异性且受多种刺激因素调控 ${ }^{[13]}$. 同时, lncRNAs的转录发生在生物体发育过程中特定的时间 和组织中, 转录过程受到严格的调控. IncRNAs的启动 子区域以及剪切位点与蛋白编码基因具有一定的相似 性 $^{[14]}, \operatorname{lncRNAs}$ 转录剪切后即可折叠成特定的三级结 构, 与多种生物大分子相互作用, 不需要翻译过程, 因 此IncRNAs 可以作为效应物提高调控效率 ${ }^{[15,16]}$.

\subsection{IncRNAs 在人类疾病中的作用}

越来越多的lncRNAs被鉴定为人类疾病的重要调 节因子, 它们通过各种机制参与细胞过程, 发挥信号转 导、诱饵、引导及支架等作用 ${ }^{[17]}$. 例如, 在DNA损伤 刺激后, P53蛋白诱导转录产生IncRNA PANDA, 通过 作用于核转录因子NF-YA，从而抑制调亡前体基因的 表达, 破坏NF-YA依赖的调亡通路, 使细胞周期停 滞 ${ }^{[18]}$. IncRNA HOTAIR 可作为支架募集PRC2, 导致 $\mathrm{H} 3 \mathrm{~K} 27$ 甲基化, 改变基因表达水平, 增加癌症的侵袭 和转移能力, 反之HOTAIR的缺失可以抑制癌症 ${ }^{[19]}$. lncRNA $B A C E 1-A S$ 可与BACE1 mRNA形成RNA双链, 增强BACE1 mRNA的稳定性, 这表明lncRNA在阿尔 兹海默症发展过程中发挥重要作用 ${ }^{[20]}$. 另有文献报道, IncRNA $B G L 3$ 可作为一种竞争性内源RNA与microRNA结合, 有利于肿瘤抑制基因 $P T E N$ 的翻译 ${ }^{[21]}$.

\subsection{IncRNAs在病毒感染中的作用}

研究人员已证明 $\operatorname{lncRNAs}$ 在病毒感染和抗病毒免 疫反应中起重要作用. 报道称 $A$ 型流感病毒(IAV)、丙 型肝炎病毒(hepatitis C virus, HCV)、人免疫缺陷病毒 (human immunodeficiency virus, HIV)、单纯疮疹病毒 (herpes simplex virus, HSV)等均能调节宿主细胞中多 种IncRNAs的表达. IncRNA GAS5 通过与HCV NS3蛋白 结合, 抑制 $\mathrm{HCV}$ 感染 ${ }^{[22]}$, 而IncRNA CMPK2 作为调控编 码蛋白ISGs的负调节因子, 敲低后可抑制HCV复制 ${ }^{[23]}$. IncRNA NEATl可增强IL8的转录, 调节HIV-1转录后表 达 ${ }^{[24,25]}$. IncRNA NKILA 可通过阻断IKK诱导的NF- $\mathrm{kB}$ 磷 酸化, 防止IKB降解来抑制NF-kB信号转导 ${ }^{[26]}$. IAV感染 诱导的IncRNA $N R A V$ 可抑制干扰素诱导基因的转录, 从而负向调节抗病毒天然免疫过程 ${ }^{[7]}$, 其关键因子如 何参与信号通路来增强IFN- $\beta$ 产生的机理尚未明确.

\section{2 在流感病毒感染过程中IncRNAs表达变 化及调控作用}

流感病毒寄生于宿主细胞中, 依赖细胞促进自身 复制并抑制宿主的抗病毒反应. 在流感病毒生命周期 中, 病毒和宿主细胞之间存在着相互作用及表达调控. 2010年，Peng等人 ${ }^{[8]}$ 发现流感病毒诱导小鼠胚胎成纤 维细胞中大量 $\operatorname{lncRNAs}$ 差异性表达，随后Josset等人 ${ }^{[6]}$ 也证实了这一现象, 这提示 $1 n c R N A s$ 在流感病毒与宿 主的互作中发挥重要作用. 一系列研究证明, lncRNAs 在流感病毒感染过程中通过表观遗传学修饰、干扰素 依赖或非依赖等方式发挥着调控作用(表1).

\subsection{IncRNAs 调控宿主细胞天然免疫}

天然免疫作为宿主机体的防御屏障对抵御病毒的 侵袭发挥着重要的作用. 流感病毒感染宿主细胞后, 宿 主细胞可以通过模式受体来识别病原相关模式分子, 从而激活宿主天然免疫反应, 进而诱导干扰素和促炎 症细胞因子等抗病毒因子的产生, 诱发抗病毒天然免 疫反应 ${ }^{[39]}$. Guttman等人 ${ }^{[40]}$ 利用脂多糖刺激小鼠骨髓 来源的树突状细胞诱导产生了 20 个 lncRNAs, 首次证 明IncRNAs在宿主细胞天然免疫反应中发挥着潜在作 用. IncRNAs通过碱基互补配对和形成特定的空间结 构, 与DNA, mRNA, microRNA及蛋白质等生物大分 
表 1 在流感病毒感染过程中发挥调控作用的宿主IncRNAs

\begin{tabular}{|c|c|c|c|c|c|}
\hline lncRNAs & 简述 & 诱导因素 & 转录情况 & 功能及作用机制 & 参考文献 \\
\hline NEAT1/VINC/Linc00084 & $\begin{array}{c}\text { 核旁斑点组装转录本 } 1 \text {, 病 } \\
\text { 毒诱导的非编码RNA }\end{array}$ & $\begin{array}{l}\text { IAV, HSV, HIV, HTNV, } \\
\text { polyI:C }\end{array}$ & 上调 & $\begin{array}{c}\text { 通过与SFPQ相互作用并将 } \\
\text { 其重新定位来促进抗病毒 } \\
\text { IL8的表达; 增加RIG-I和 } \\
\text { DDX60的表达, 导致IFN- } \beta \\
\text { 的产生增加 }\end{array}$ & {$[24,25,27 \sim 29]$} \\
\hline NRAV/DYNLL1-AS1 & $\begin{array}{l}\text { 抗病毒的负调节剂, } \\
\text { DYNLL1的反义RNA }\end{array}$ & IAV, SeV, HSV, MDRV & 下调 & $\begin{array}{c}\text { 通过促进H3K27me3(转录 } \\
\text { 抑制标记)和抑制其启动子 } \\
\text { 上的H3K4me3(转录激活标 } \\
\text { 记)来抑制MxA和IFITM3基 } \\
\text { 因的转录, 从而有利于病毒 } \\
\text { 复制 }\end{array}$ & [7] \\
\hline BISPR/LncBST2 & $\begin{array}{c}\text { BST2干扰素刺激正向调 } \\
\text { 节因子 }\end{array}$ & $\begin{array}{c}\text { IFN- } \alpha 2, \text { IFN-1, IAV } \\
(\text { PR8 } 8 \text { NS1), VSV(M51R), } \\
\text { HCV, HEV }\end{array}$ & 上调 & $\begin{array}{c}\text { 促进抗病毒ISG BST2/ } \\
\text { tetherin的表达 }\end{array}$ & {$[30,31]$} \\
\hline EGOT & $\begin{array}{c}\text { 嗜酸性粒细胞个体发育转 } \\
\text { 录本 }\end{array}$ & IFN- $\alpha 2$, IAV, HCV, SFV & 上调 & $\begin{array}{c}\text { 抑制ISGs(GBP1,ISG15, } \\
\text { Mx1,BST2,ISG56,IFI6和 } \\
\text { IFITM1)的表达 }\end{array}$ & {$[32]$} \\
\hline ACOD1/LOC102637961 & $\begin{array}{c}\text { 通过其邻近的编码基因 } \\
\text { Acod1鉴定的1ncRNA }\end{array}$ & $\begin{array}{l}\text { IAV, HSV, SeV, VSV, } \\
\text { VACV }\end{array}$ & 上调 & $\begin{array}{c}\text { 通过与GOT2相互作用促进 } \\
\text { 病毒感染和复制, 并增加其 } \\
\text { 催化活性, 以产生病毒复制 } \\
\text { 所需的关键代谢物 }\end{array}$ & {$[33,34]$} \\
\hline VIN/Linc01191 & 病毒诱导型1ncRNA & IAV, VSV & 上调 & $\begin{array}{c}\text { 位于细胞核内, 通过干扰素 } \\
\text { 非依赖途径有利于病毒蛋 } \\
\text { 白(HA, NP, NS1和M2)的表 } \\
\text { 达和病毒的复制 }\end{array}$ & [35] \\
\hline ISG20/ NONHSAG017802 & $\begin{array}{l}\text { 与ISG20定位到相同染色 } \\
\text { 体位点, 大部分序列相同 }\end{array}$ & IAV, SeV, polyI:C, IFN- $\beta$ & 上调 & $\begin{array}{c}\text { lnc-ISG20作为内源竞争性 } \\
\text { RNA结合miR-326, 将ISG20 } \\
\text { 的mRNA释放出来, 从而抑 } \\
\text { 制IAV复制的机制 }\end{array}$ & [36] \\
\hline PAAN/ LINC01988 & PA相关非编码RNA & IAV & 上调 & $\begin{array}{l}\text { IAV对lncRNA-PAAN表达 } \\
\text { 的特异性上调, IncRNA- } \\
\text { PAAN能结合PA促进病毒 } \\
\text { RNA聚合酶的组装, 因此保 } \\
\text { 证了有效的病毒RNA合成 }\end{array}$ & {$[37]$} \\
\hline ISG15 & 邻近ISG15 & $\begin{array}{c}\text { IFN- } \alpha 2, \text { IFN- } \lambda, \text { IAV } \\
(\mathrm{PR} 8 \Delta \mathrm{NS} 1), \mathrm{VSV}(\mathrm{M} 51 \mathrm{R}) \\
\text { HCV1 }\end{array}$ & 上调 & NA & {$[30]$} \\
\hline ISR2 & GBP1的假基因 & $\begin{array}{c}\text { IFN- } \alpha 2, \text { IFN- } \beta, \text { HCV1, IAV } \\
\text { (PR8 } 8 \text { NS1), HIV }\end{array}$ & 上调 & NA & {$[38]$} \\
\hline ISR8/ AC116366.6 & 邻近 IRF1 & $\begin{array}{c}\text { IFN- } \alpha 2, \text { IFN- } \beta, \text { HCV1, IAV } \\
\text { (PR8 } 8 \text { NS1) }\end{array}$ & 上调 & NA & {$[38]$} \\
\hline
\end{tabular}

子互作, 在宿主细胞天然免疫中影响基因的表达, 包括 组蛋白修饰、与转录因子的互作、特定蛋白的转录 等 $^{[41]}$.

组蛋白修饰是基因转录调控的关键步骤, Wang等 ${ }^{[15]}$ 提出 $\operatorname{lncRNAs}$ 参与该过程的调控. IncRNAs能将组 蛋白修饰复合物募集到特定的基因，如IncRNA NeST 通过与WDR5结合招募MLL/Ash2L/RbBP5复合物，从
而反式激活 $\gamma$ 干扰素基因 ${ }^{[42]}$. 此外, IncRNAs还通过对 转录起始位点的组蛋白修饰调节宿主的抗流感先天免 疫应答. Ouyang等人 ${ }^{[7]}$ 发现在流感病毒感染宿主细胞 后由dynll1基因反义链转录的IncRNA $N R A V$ 表达水平 显著下调, 而抗病毒蛋白MxA和IFITM3的表达显著上 升, 进一步研究表明, NRAV降低导致转录起始位点组 蛋白 $\mathrm{H} 3$ 上的 $\mathrm{K} 4$ 的三甲基化显著增加，而K27的三甲基 
化显著减少 $(\mathrm{H} 3 \mathrm{~K} 4 \mathrm{me} 3$ 为转录激活标记, $\mathrm{H} 3 \mathrm{~K} 27 \mathrm{me} 3$ 为 转录抑制标记), 从而使得关键的抗流感病毒干扰素诱 导基因MxA和IFITM3 表达量增加来抑制流感病毒.

lncRNAs 可通过与转录因子的互作来发挥作用. 细胞核内的1ncRNAs可通过与基因特异性转录激活因 子结合, 传导细胞信号并抑制其活性, 如PANDA和 Gas $5^{[18,43]}$. 由poly I:C诱导上调的IncRNA NEAT1, 参 与一系列先天免疫相关基因的表达，如IL8, RIG- I 和 DDX60 $0^{[24,27,44]}$. 研究发现NEAT1对RNA聚合酶 II 转录 有关的核旁斑点的形成必不可少，并且核旁斑点可与 人脯氨酸/谷氨酰胺富含性剪接因子 (SFPQ/PSF) 结 合 ${ }^{[45-48]}, \mathrm{SFPQ} / \mathrm{PSF}$ 则充当IL8启动子的抑制剂. 流感病 毒入侵导致NEAT 1 上调，促进大量核旁斑点形成， SFPQ/PSF从IL8启动子转移至核旁斑点，从而激活抗 病毒IL8的表达 ${ }^{[24]}$.

$\operatorname{lncRNAs}$ 参与调控转录和特定基因的表达. lncRNAs 可通过RNA聚合酶 II 来调控大多数的转录, 从而影响宿主天然免疫相关基因的转录. 如IL- $1 \alpha$ 的反 义产物AS-IL $1 \alpha$ 位于细胞核中, 并未改变IL-1 $\alpha$ mRNA 的稳定性，相反AS-IL1 $\alpha$ 能将RNA聚合酶 II 募集到IL$1 \alpha$ 启动子 ${ }^{[49]}$. IncRNAs 还可以通过与异质核糖核蛋白 (hnRNPs)相互作用来调控转录. 如lncRNA THRIL与 hnRNP-L， lncRNACox2与hnRNP-A/B和A2/B1相互作 用分别来调控 TNF- $\alpha$ 和 CCL 5 的转录 ${ }^{[50,51]}$. 另外, lncRNAs对基因表达的调节可通过基因座特异性的方 式进行. IncRNA $B I S P R$ 通过充当 $\mathrm{bst} 2$ 的侧翼基因从而 调节抗病毒反应, BISPR被IAV和 I 型干扰素诱导上调, 抑制BISPR会导致ISG BST2 表达水平特异性降低 ${ }^{[30]}$.

\section{$2.2 \operatorname{IncRNAs}$ 与干扰素相关调控途径的作用}

在感染流感病毒的小鼠模型中检测到数百种 $\operatorname{lncRNAs}$ 的表达 ${ }^{[8]}$, 其中较多在 I 型干扰素信号传导的 下游起调节作用。流感病毒主要被宿主细胞的RIG$\mathrm{I}$ 样受体识别, 从而刺激 I 型干扰素的产生, 触发宿 主抗病毒级联免疫反应. 近年来, 已有文献报道称, I 型干扰素可对先天免疫系统的抗病毒作用产生广泛 影响, 其抑制病毒复制的能力在很大程度上依赖于对 干扰素刺激基因(interferon-stimulated genes，ISGs)的 诱导作用 ${ }^{[52]}$. 干扰素(interferon- $\gamma$, IFN) 是一类细胞因 子, 靶细胞在感染病毒后IFN被主动转录, 随后IFN与 其相应的受体结合, 并通过JAK-STAT信号转导途径诱
导ISGs表达, 建立抗病毒状态, 以自分泌或旁分泌方式 发挥抗病毒作用 ${ }^{[53]}$. 在IFN $\alpha$ 处理的动物肝细胞及 $\mathrm{HuH7}$ 细胞中, 均发现数百种1ncRNAs的差异表达, 包 括干扰素刺激产生的长链非编码RNAs(ISRs)和干扰 素作用下调的长链非编码RNAs(IDRs). 这些研究强烈

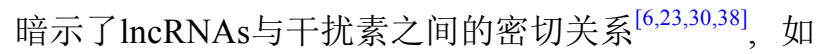
图1所示.

lncRNAs可与邻近ISGs共同表达并对其进行调控. 例如，干扰素诱导基因bst2能够抑制子代流感病毒的 释放, 从而发挥抗病毒作用 ${ }^{[54]}$. lnc BST2 与 $\mathrm{bst} 2$ 共享启 动子且在流感感染过程中共表达, 从而正向调控 bst2 基因的转录 ${ }^{[30]}$, 其中 lnc BST2 的表达依赖于JAK-STAT 信号转导途径. ISR2, ISR 8 和Inc ISG15被IFN和IAV (PR8-NS1)诱导产生, 其基因座分别接近ISGs GBP1,

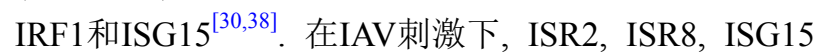
表达量和其邻近基因表达量均显著增加 ${ }^{[30,38]}$. 上述研 究表明ISR2, ISR8和ISG15在病毒感染和干扰素调控 中参与重要作用, 但具体机制尚不明确.

最近有研究发现, IncRNA NEATI在流感病毒感染 的宿主细胞中显著上调, 且细胞因子IL8的表达依赖 NEAT $1^{[24]}$, NEAT1通过RIG- I 信号传导促进干扰素反 应 $^{[27]}$. NEAT1消除SFPQ/PSF对RIG- I 和 $D D X 60$ 基因 的转录抑制作用, 从而增加转录因子IRF7的表达量, 进一步诱导表达干扰素和NEAT1，从而抑制病毒的复 制 $^{[27]}$. 除此之外, NEAT1还与HEXIM1形成多亚基复 合物与特定蛋白相互作用, 募集STING和激活IRF3, 启动 I 型干扰素的激活途径 ${ }^{[28]}$.

此外，病毒能“绑架”宿主IncRNAs，从而抑制干扰 素信号传导途径, 促进自身增殖. IncRNA EGOT可被 流感病毒诱导, 作为抗病毒反应的负调节因子 ${ }^{[32]}$. $1 \mathrm{ncRNAs}$ 能够通过干扰素非依赖途径进行调控, lncRNA $V I N$, lncRNA PAAN和lncRNA ACOD1均能被 流感病毒诱导产生且被病毒“绑架”, [33 35,37]. 研究显示 lncRNA VIN为病毒诱导型lncRNA, A型流感病毒感染 后上调 ${ }^{[35]}$, 敲除VIN可导致病毒复制和病毒基因表达 的显著减少 ${ }^{[35]}$, 而VIN如何促进病毒基因表达和复制 仍有待进一步研究. Wang 等人 ${ }^{[37]}$ 研究发现, IncRNA $P A A N$ 通过与流感病毒RNA聚合酶复合物的关键组分 PA结合，促进病毒RNA聚合酶的组装和病毒RNA合 成. 有趣的是, IncRNA $A C O D 1$ 可通过调节宿主细胞 代谢来促进流感病毒感染, 它直接与细胞质中的代谢 


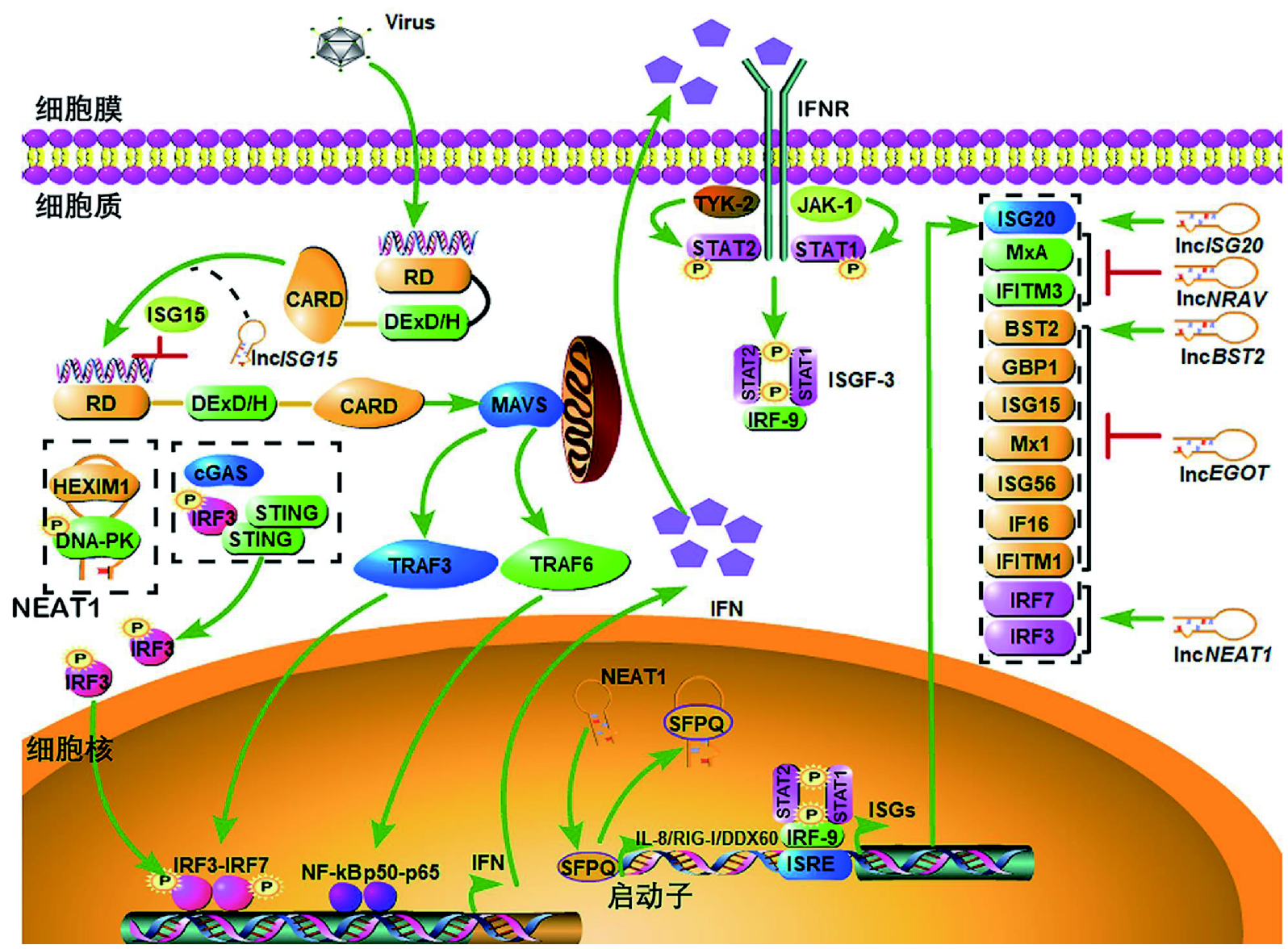

图 1 IncRNAs与干扰素调控途径的作用模式图(网络版彩图)

酶谷氨酸-草酰乙酸转氨酶(GOT2)结合, 导致该酶的催 化活性增加，增强病毒复制所需的关键代谢物的产 生 ${ }^{[33,34]}$, 从而促进病毒复制.

\section{IncRNAs与miRNAs互作在流感病毒感 染过程中的作用}

miRNAs是一类约 22 个核苷酸的小非编码RNA, 通过对转录后基因调控参与不同的生物学过程. 大多 数miRNAs基因由RNA聚合酶 II 转录, 经酶切后形成 具有茎-环结构的前体miRNAs(pre-miRNAs) ${ }^{[55]}$. PremiRNAs和(RNA-induced silencing complex, RISC)特 定蛋白形成有酶活性的 RNA 诱导沉默复合物 $(\mathrm{RISC})^{[56-59]}$ ，通过酶消化后产生成熟的miRNAs. 近年 来不少与疾病相关的研究报道称 miRNAs与 ncRNAs 存在着相互作用(表2).

\section{1 miRNAs可调控IncRNAs的表达丰度}

Yoon等人 ${ }^{[60,61]}$ 研究表明，RNA结合蛋白HuR被招 募和促进miRNA let7家族成员与RISC中Ago2蛋白结 合, 从而导致lncRNA $p 21$ 及lncRNA HOTAIR的稳定性 降低，从而分别抑制靶标mRNAs的翻译和促进蛋白质 的泛素化. Gernapudi等人 ${ }^{[62]}$ 研究发现, 在细胞核中的 成熟miR-140可以与NEAT1相互作用，导致NEAT1表 达增加，从而促进脂肪的生成. 在流感病毒的研究中, miRNAs通过靶向流感病毒基因或宿主基因, 调节病毒 基因的表达或调控流感病毒诱导的宿主细胞多种生物 学过程，进而影响病毒的复制. $\mathrm{Ma}$ 等人 ${ }^{[67]}$ 研究发现, miRNA let-7c被流感病毒诱导上调, let-7c能通过抑制 流感病毒M1蛋白的表达，从而抑制流感病毒的复制. miR-33a由H1N1，H9N2，H3N2亚型流感病毒诱导上 调，通过靶向ARCN1并抑制病毒核糖核蛋白活性来干 扰IAV复制 ${ }^{[68]}$. miR-136由流感病毒H5N1诱导上调, 作 
表 2 IncRNAs与 miRNAs的相互作用汇总

\begin{tabular}{|c|c|c|c|c|}
\hline lncRNAs & microRNAs & 相互作用关系 & 相互作用后产生结果 & 参考文献 \\
\hline $\mathrm{p} 21$ & let- $7 \mathrm{~b}$ & lncRNA降解 & $\begin{array}{c}\text { JUNB和CTNNB mRNA翻译被 } \\
\text { 抑制 }\end{array}$ & [60] \\
\hline HOTAIR & let- $7 \mathrm{~b}$ & lncRNA降解 & 抑制Ataxin-1和Snurportin-1泛素化 & {$[61]$} \\
\hline NEAT1 & $\operatorname{miR}-140$ & 上调IncRNA & 促进脂肪生成 & [62] \\
\hline LOC553103 & EBV-miR-BART6-3p & 下调 IncRNA & $\begin{array}{c}\text { 抑制EBV相关的癌细胞迁移和 } \\
\text { 侵袭 }\end{array}$ & {$[63]$} \\
\hline ISG20 & $\operatorname{miR}-326$ & 诱捕miRNA & $\begin{array}{c}\text { 促进ISG20的表达, 从而抑制流感 } \\
\text { 病毒的复制 }\end{array}$ & [36] \\
\hline BACE1 & $\operatorname{miR}-485-5 \mathrm{p}$ & 竞争结合mRNA & 增强BACE1 mRNA的稳定性 & {$[20]$} \\
\hline H19 & $\begin{array}{c}\text { let-7a,b,g,I; miR-675-5p; } \\
\text { miR-675-3p }\end{array}$ & 诱捕miRNA; miRNA前体 & $\begin{array}{c}\text { 降低let-7家族的靶向性; } \\
\text { 产生新的miRNA }\end{array}$ & [64 66] \\
\hline BGL3 & $\begin{array}{l}\text { miR-17, miR-93, miR-20a, miR-20b, } \\
\text { miR-106a, miR-106b }\end{array}$ & 诱捕miRNA & 促进肿瘤抑制基因PTEN的翻译 & {$[21]$} \\
\hline
\end{tabular}

为RIG- I 的免疫激动剂起作用，引起IL-6和IFN- $\beta$ 的增 加 $^{[69]}$.

\subsection{IncRNAs可诱捕miRNAs 来调控mRNA的翻译 和稳定}

$\operatorname{lncRNAs}$ 可作为竞争性内源RNA(ceRNA) 诱捕 miRNAs发挥作用. 因1ncRNAs中存在miRNAs靶向的 $m R N A s$ 的序列，通过相似序列诱捕 miRNAs 与 lncRNAs结合并将mRNA释放出来，从而拮抗miRNAs 的功能. 研究发现, miR-326是ISG20和Inc ISG20的共 有miRNA，它作用于ISG20 mRNA的3'UTR，抑制 ISG20的翻译. 证实 $1 \mathrm{nc} I S G 20$ 可作为一种ceRNA与 miR-326结合，降低其对ISG20 mRNA的抑制作用，从 而提高ISG20蛋白水平，达到抑制流感病毒复制的作 用 ${ }^{[36]}$.

$\operatorname{lncRNAs}$ 除了以 $\mathrm{ceRNA}$ 的方式发挥作用外, lncRNAs 还可以与miRNAs 竞争性结合目标mRNAs. 例如 IncRNA $B A C E 1$ 是 $\mathrm{BACE}$ 1部分序列反义互补的 lncRNAs，通过与BACE1的mRNAs的序列互补配对形 成双链, 从而增强BACE1 mRNA的稳定性且阻止miR485-5p 与之结合，避免miRNA-RISC介导的RNA降 解 ${ }^{[70]}$. 另外, lncRNAs可以作为miRNAs产生的前体, 通过细胞内RNA剪接产生特异性miRNAs并增强靶标 mRNAs的转录后调节 ${ }^{[64-66]}$. 以上为研究流感病毒提供 了较好的切入点和研究思路.

\section{4 总结与展望}

流感病毒感染宿主机体的过程中能诱导机体产生 大量的IncRNAs, 研究IncRNAs如何在病毒感染中发挥 作用, 如何调控宿主的抗病毒免疫反应, 对于流感病毒 跨物种传播及病毒性疾病的防控将具有指导意义. 目 前对lncRNAs在流感病毒复制和如何参与先天免疫调 控的研究非常少, 现有的研究仅局限于发现IAV感染 宿主后lncRNAs存在差异表达这一现象，但宿主所产 生的IncRNAs在调节宿主免疫反应中所发挥的作用及 其调控抗病毒天然免疫应答的机制尚不清楚.

有些lncRNAs具有病毒特异性，如lncRNA PAAN 只被IAV诱导，而不被HIV-1的VSV-G假病毒、EV71 及ZIKV诱导 ${ }^{[37]}$ ，IncRNA VIN 能被IAV诱导，而不被B 型流感病毒(influenza B virus, IBV)诱导 ${ }^{[35]}$. 对于IBV而 言，现无IBV诱导宿主细胞产生的IncRNAs的报道. 在 病毒感染的细胞中，宿主和病毒基因编码的各种非编 码RNA在宿主和病毒之间的相互作用中形成调节网 络，因此，lncRNA和miRNA之间的相互作用可以作为 研究工作较好的切入点. 另外, 最近的全基因组研究表 明，在脊椎动物中数以百种功能性微肽可能被 $\operatorname{lncRNAs}$ 编码 ${ }^{[71]}$ ，这使得现有长链非编码RNA的定义 受到挑战，也为 $\operatorname{lncRNAs}$ 的研究提供了新的思路. 同 时, 在研究IncRNAs调控流感病毒的机制中, 能否发现 一些被流感病毒“绑架”的宿主IncRNAs对其复制作用， 也是我们后续的研究重点. 现研究多局限于lncRNAs 
参与JAK-STAT途径, 然而除了JAK-STAT途径, IFNs还 通过激活其他STAT非依赖性途径起作用，如丝裂原活 化蛋白激酶(MAPKs)p38，细胞外信号调节激酶(extracellular signal regulated kinase, ERKs) 以及磷脂酰肌醇 3-激酶(phosphoinositide 3-kinases, PI3Ks) 途径 ${ }^{[72,73]}$, 能
否发现一些参与IFNs激活的其它信号通路，也是后续 的研究方向.

综上所述，阐明在流感病毒感染中 $1 n c R N A s$ 的功 能，有利于我们揭示流感病毒感染致病的作用，为开 发新的抗流感病毒药物开辟新的途径及理论支撑.

\section{参考文献}

1 Krug R M. An RNA-synthesizing machine. Nature, 2014, 516: 338-339

2 Paules C I, Marston H D, Eisinger R W, et al. The pathway to a universal influenza vaccine. Immunity, 2017, 47: 599-603

3 Smith G J D, Vijaykrishna D, Bahl J, et al. Origins and evolutionary genomics of the 2009 swine-origin H1N1 influenza A epidemic. Nature, 2009, 459: 1122-1125

4 Ponting C P, Oliver P L, Reik W. Evolution and functions of long noncoding rnas. Cell, 2009, 136: 629-641

5 Djebali S, Davis C A, Merkel A, et al. Landscape of transcription in human cells. Nature, 2012, 489: 101-108

6 Josset L, Tchitchek N, Gralinski L E, et al. Annotation of long non-coding rnas expressed in collaborative cross founder mice in response to respiratory virus infection reveals a new class of interferon-stimulated transcripts. RNA Biol, 2014, 11: 875-890

7 Ouyang J, Zhu X, Chen Y, et al. NRAV, a long noncoding RNA, modulates antiviral responses through suppression of interferon-stimulated gene transcription. Cell Host Microb, 2014, 16: 616-626

8 Peng X, Gralinski L, Armour C D, et al. Unique signatures of long noncoding RNA expression in response to virus infection and altered innate immune signaling. mBio, 2010, 1, doi: 10.1128/mBio.00206-10

9 Kung J T Y, Colognori D, Lee J T. Long noncoding RNAs: past, present, and future. Genetics, 2013, 193: 651-669

10 Quinn J J, Chang H Y. Unique features of long non-coding RNA biogenesis and function. Nat Rev Genet, 2016, 17: 47-62

11 Hung T, Chang H Y. Long noncoding RNA in genome regulation. RNA Biol, 2010, 7: 582-585

12 Pink R C, Wicks K, Caley D P, et al. Pseudogenes: pseudo-functional or key regulators in health and disease? RNA, 2011, 17: 792-798

13 Cabili M N, Trapnell C, Goff L, et al. Integrative annotation of human large intergenic noncoding RNAs reveals global properties and specific subclasses. Genes Dev, 2011, 25: 1915-1927

14 Ponjavic J, Ponting C P, Lunter G. Functionality or transcriptional noise? Evidence for selection within long noncoding RNAs. Genome Res, 2007, 17: 556-565

15 Wang K C, Chang H Y. Molecular mechanisms of long noncoding RNAs. Mol Cell, 2011, 43: 904-914

$16 \mathrm{Xu} \mathrm{C} \mathrm{G}$, Yang M F, Ren Y Q, et al. Exosomes mediated transfer of lncrna uca1 results in increased tamoxifen resistance in breast cancer cells. Eur Rev Med Pharmacol Sci, 2016, 20: 4362-4368

17 Ouyang J, Hu J, Chen J L. Lncrnas regulate the innate immune response to viral infection. WIREs RNA, 2016, 7: 129-143

18 Hung T, Wang Y, Lin M F, et al. Extensive and coordinated transcription of noncoding rnas within cell-cycle promoters. Nat Genet, 2011, 43: $621-629$

19 Gupta R A, Shah N, Wang K C, et al. Long non-coding rna hotair reprograms chromatin state to promote cancer metastasis. Nature, 2010, 464: $1071-1076$

20 Faghihi M A, Modarresi F, Khalil A M, et al. Expression of a noncoding RNA is elevated in Alzheimer's disease and drives rapid feed-forward regulation of $\beta$-secretase. Nat Med, 2008, 14: 723-730

21 Guo G, Kang Q, Zhu X, et al. A long noncoding RNA critically regulates Bcr-Abl-mediated cellular transformation by acting as a competitive endogenous RNA. Oncogene, 2015, 34: 1768-1779

22 Qian X, Xu C, Zhao P, et al. Long non-coding RNA gas5 inhibited hepatitis c virus replication by binding viral ns3 protein. Virology, 2016, 492: $155-165$

23 Kambara H, Niazi F, Kostadinova L, et al. Negative regulation of the interferon response by an interferon-induced long non-coding RNA. Nucl Acids Res, 2014, 42: 10668-10680

24 Imamura K, Imamachi N, Akizuki G, et al. Long noncoding RNA neat1-dependent sfpq relocation from promoter region to paraspeckle mediates 
il8 expression upon immune stimuli. Mol Cell, 2014, 53: 393-406

Zhang Q, Chen C Y, Yedavalli V S R K, et al. Neat1 long noncoding RNA and paraspeckle bodies modulate hiv-1 posttranscriptional expression. mBio, 2013, 4: e00596

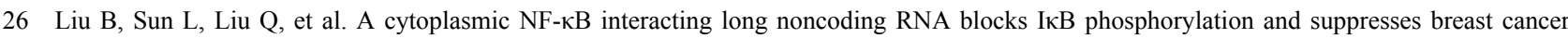
metastasis. Cancer Cell, 2015, 27: 370-381

27 Ma H, Han P, Ye W, et al. The long noncoding RNA NEAT1 exerts antihantaviral effects by acting as positive feedback for RIG-I signaling. J Virol, 2017, 91

28 Morchikh M, Cribier A, Raffel R, et al. Hexim1 and neat1 long non-coding RNA form a multi-subunit complex that regulates DNA-mediated innate immune response. Mol Cell, 2017, 67: 387-399.e5

29 Wang Z, Fan P, Zhao Y, et al. NEAT1 modulates herpes simplex virus-1 replication by regulating viral gene transcription. Cell Mol Life Sci, 2017, 74: 1117-1131

30 Barriocanal M, Carnero E, Segura V, et al. Long non-coding RNA BST2/BISPR is induced by IFN and regulates the expression of the antiviral factor tetherin. Front Immunol, 2015, 5

31 Paliwal D, Joshi P, Panda S K. Hepatitis E Virus (HEV) egress: role of BST2 (tetherin) and interferon induced long non- coding RNA (lncRNA) bispr. PLoS ONE, 2017, 12: e0187334

32 Carnero E, Barriocanal M, Prior C, et al. Long noncoding RNA EGOT negatively affects the antiviral response and favors HCV replication. EMBO Rep, 2016, 17: 1013-1028

33 Kotzin J J, Mowel W K, Henao-Mejia J. Viruses hijack a host lncRNA to replicate. Science, 2017, 358: $993-994$

34 Wang P, Xu J, Wang Y, et al. An interferon-independent lncRNA promotes viral replication by modulating cellular metabolism. Science, 2017, 358: 1051-1055

35 Winterling C, Koch M, Koeppel M, et al. Evidence for a crucial role of a host non-coding RNA in influenza a virus replication. RNA Biol, 2014, 11: $66-75$

36 Chai W, Li J, Shangguan Q, et al. Lnc-ISG20 inhibits influenza a virus replication by enhancing ISG20 expression. J Virol, 2018, 92

37 Wang J, Wang Y, Zhou R, et al. Host long noncoding RNA lncRNA-PAAN regulates the replication of influenza A virus. Viruses, 2018, 10: 330

38 Carnero E, Barriocanal M, Segura V, et al. Type I interferon regulates the expression of long non-coding RNAs. Front Immunol, 2014, 5: 548

39 McNab F, Mayer-Barber K, Sher A, et al. Type I interferons in infectious disease. Nat Rev Immunol, 2015, 15: 87-103

40 Guttman M, Amit I, Garber M, et al. Chromatin signature reveals over a thousand highly conserved large non-coding RNAs in mammals. Nature, 2009, 458: 223-227

41 Mercer T R, Mattick J S. Structure and function of long noncoding RNAs in epigenetic regulation. Nat Struct Mol Biol, 2013, 20: 300-307

42 Gomez J A, Wapinski O L, Yang Y W, et al. The NeST long ncRNA controls microbial susceptibility and epigenetic activation of the interferon- $\gamma$ locus. Cell, 2013, 152: 743-754

43 Kino T, Hurt D E, Ichijo T, et al. Noncoding RNA gas5 is a growth arrest- and starvation-associated repressor of the glucocorticoid receptor. Sci Signal, 2010, 3: ra8

44 Saha S, Murthy S, Rangarajan P N. Identification and characterization of a virus-inducible non-coding RNA in mouse brain. J General Virol, 2006, 87: 1991-1995

45 Chen L L, Carmichael G G. Long noncoding RNAs in mammalian cells: what, where, and why? WIREs RNA, 2010, 1: 2-21

Clemson C M, Hutchinson J N, Sara S A, et al. An architectural role for a nuclear noncoding rna: Neat1 RNA is essential for the structure of paraspeckles. Mol Cell, 2009, 33: 717-726

47 Sasaki Y T F, Ideue T, Sano M, et al. MEN\&/ $\beta$ noncoding RNAs are essential for structural integrity of nuclear paraspeckles. Proc Natl Acad Sci USA, 2009, 106: 2525-2530

48 Sunwoo H, Dinger M E, Wilusz J E, et al. MEN $\varepsilon / \beta$ nuclear-retained non-coding RNAs are up-regulated upon muscle differentiation and are essential components of paraspeckles. Genome Res, 2009, 19: 347-359

49 Chan J, Atianand M, Jiang Z, et al. Cutting edge: a natural antisense transcript, AS-IL1 $\alpha$, controls inducible transcription of the proinflammatory cytokine IL-1 $\alpha$. J Immunol, 2015, 195: 1359-1363

50 Carpenter S, Aiello D, Atianand M K, et al. A long noncoding RNA mediates both activation and repression of immune response genes. Science, 2013, 341: 789-792 
51 Li Z, Chao T C, Chang K Y, et al. The long noncoding RNA THRIL regulates TNF $\alpha$ expression through its interaction with hnRNPL. Proc Natl Acad Sci USA, 2014, 111: 1002-1007

52 Schoggins J W, Wilson S J, Panis M, et al. A diverse range of gene products are effectors of the type I interferon antiviral response. Nature, 2011, 472: 481-485

53 Borden E C, Sen G C, Uze G, et al. Interferons at age 50: past, current and future impact on biomedicine. Nat Rev Drug Discov, 2007, 6: 975-990

54 Mangeat B, Cavagliotti L, Lehmann M, et al. Influenza virus partially counteracts restriction imposed by tetherin/bst-2. J Biol Chem, 2012, 287: 22015-22029

55 Okamura K, Hagen J W, Duan H, et al. The mirtron pathway generates microrna-class regulatory RNAs in Drosophila. Cell, 2007, 130: 89-100

56 Bartel D P. MicroRNAs: genomics, biogenesis, mechanism, and function.. Cell, 2004, 116: 281-297

57 Ghildiyal M, Zamore P D. Small silencing RNAs: an expanding universe. Nat Rev Genet, 2009, 10: 94-108

58 Vasudevan S, Tong Y, Steitz J A. Switching from repression to activation: micrornas can up-regulate translation. Science, 2007, 318: 1931-1934

59 Song L, Liu H, Gao S, et al. Cellular microRNAs inhibit replication of the H1N1 influenza a virus in infected cells. J Virol, 2010, 84: 8849-8860

60 Yoon J H, Abdelmohsen K, Srikantan S, et al. Lincrna-p21 suppresses target mRNA translation. Mol Cell, 2012, 47: 648-655

61 Yoon J H, Abdelmohsen K, Kim J, et al. Scaffold function of long non-coding RNA hotair in protein ubiquitination. Nat Commun, 2013, 4: 2939

62 Gernapudi R, Wolfson B, Zhang Y, et al. miR-140 promotes expression of long non-coding RNA NEAT1 in Adipogenesis. Mol Cell Biol, 2015, 311: MCB.00702-15

$63 \mathrm{He} \mathrm{B}, \mathrm{Li} \mathrm{W}, \mathrm{Wu}$ Y, et al. Epstein-barr virus-encoded mir-bart6-3p inhibits cancer cell metastasis and invasion by targeting long non-coding RNA loc553103. Cell Death Dis, 2016, 7: e2353

64 Cai X, Cullen B R. The imprinted h19 noncoding RNA is a primary microrna precursor. RNA, 2007, 13: 313-316

65 Kallen A N, Zhou X B, Xu J, et al. The imprinted h19 lncRNA antagonizes let-7 microRNAs. Mol Cell, 2013, 52: 101-112

66 Vennin C, Spruyt N, Dahmani F, et al. $H 19$ non coding RNA-derived miR-675 enhances tumorigenesis and metastasis of breast cancer cells by downregulating c-Cbl and Cbl-b. Oncotarget, 2015, 6: 29209-29223

67 Ma Y J, Yang J, Fan X L, et al. Cellular microRNA let-7c inhibits $\mathrm{m} 1$ protein expression of the H1N1 influenza a virus in infected human lung epithelial cells. J Cell Mol Med, 2012, 16: 2539-2546

$68 \mathrm{Hu}$ Y, Jiang L, Lai W, et al. Microrna-33a disturbs influenza a virus replication by targeting arcn1 and inhibiting viral ribonucleoprotein activity. J General Virol, 2016, 97: 27-38

69 Zhao L, Zhu J, Zhou H, et al. Identification of cellular microRNA-136 as a dual regulator of RIG-I-mediated innate immunity that antagonizes H5N1 IAV replication in a549 cells. Sci Rep, 2015, 5: 14991

70 Faghihi M A, Zhang M, Huang J, et al. Evidence for natural antisense transcript-mediated inhibition of microRNA function. Genom Biol, 2010, 11: R56

71 Anderson D M, Anderson K M, Chang C L, et al. A micropeptide encoded by a putative long noncoding RNA regulates muscle performance. Cell, 2015, 160: 595-606

72 Platanias L C. Mechanisms of type- I - and type- II -interferon-mediated signalling. Nat Rev Immunol, 2005, 5: 375-386

73 Wang F, Ma Y, Barrett J W, et al. Disruption of ERK-dependent type I interferon induction breaks the myxoma virus species barrier. Nat Immunol, 2004, 5: 1266-1274 


\title{
Regulation of influenza virus infection by long non-coding RNAs
}

\author{
MIN Jie ${ }^{1,2}$, CAO Ying ${ }^{1,3}$, LI Jing ${ }^{1,2^{*}}$ \& LIU WenJun ${ }^{1,2^{*}}$ \\ 1 Key Laboratory of Pathogenic Microbiology and Immunology, Institute of Microbiology, Chinese Academy of Sciences, Beijing 100101, China; \\ 2 University of Chinese Academy of Sciences, Beijing 100049, China; \\ 3 School of Life Sciences, University of Science and Technology of China, Hefei 23000, China
}

Long non-coding RNA is a class of RNA molecules in which transcripts are longer than 200 nt, involved in the biological activities such as pre-transcriptional regulation, transcriptional regulation, and post-transcriptional regulation. The influenza viruses have a wide host spectrum and can infect animals such as humans, poultry, horses, and swine. Through its significant interaction with its hosts, these viruses have stirred up numerous worldwide pandemics and have caused serious threats to human health, as well as the industry of livestock and poultry. Recent studies have demonstrated that the infection of influenza viruses can also induce the production of a large number of lncRNAs in the host. These lncRNAs can interact with a variety of biological macromolecules and directly or indirectly play critical regulatory roles in the host's antiviral pathway or in the replication of influenza virus. This has made it necessary and meaningful to study and reveal the roles of these lncRNAs with respect to the infection and replication of influenza viruses in order to elucidate the pathogenesis mechanism of influenza virus. In view of the above, this paper presents a review of the behaviors of the lncRNAs, which are detrimental to the infection of influenza virus, to enhance our understanding of lncRNAs and provide more insight for the prevention and control of influenza.

influenza virus, long non-coding RNAs, infection, innate immunity

doi: $10.1360 / \mathrm{N} 052018-00190$ 